The few existing statistics reveal that late ophthalmic involvements in herpes zoster occur in the following order of frequency (not mentioning keratitis):-

Iridocyclitis (usually a complication with keratitis)

Optic neuritis

Paralysis of the III, IV and VI cranial nerves.

Retrobulbar neuritis has not been described at all.

\title{
Summary
}

A case of acute retrobulbar neuritis and one of VIth nerve paresis have been described. Full investigation revealed that the aetiology of both was herpes zoster. We feel that the rarity of the cases justifies their submission for publication.

\section{REHABILITATION OF THE UNI-OCULAR PATIENT}

\author{
BY \\ C. G. SCHURR \\ HOVE
}

Most patients, during their stay in Hospital after sustaining the loss of one eye, seem to be very little conscious of disability. But as soon as they begin to mix with their relatives and friends, they become accident-conscious and inclined to exaggerate their difficulties, the more so if there is delay in payment of what they consider adequate compensation.

It seems very desirable, therefore, that active steps should be taken as soon as possible to re-educate the disabled; and such re-education can commence within a day or two of the removal of the eye.

The following account of the arrangements made in this district is put forward to promote interest in this part of the problem of rehabilitation after injury, and may stimulate further experiment.

Other areas almost certainly have more cases with which to deal. So the general outline of treatment only is given, and this in very simple language.

By the co-operation of the Rehabilitation Department of the Royal Sussex County Hospital, patients who have had an eye removed at the Sussex Eye Hospital are sent over to the Department as soon as they are allowed up. But, the rehabilitation starts while the patient is still jn bed, on the second or third day after operation. The patient is given knitting with a cotton reel and crochet hook. He usually finds it good fun, and soon becomes efficient.

On the fourth or fifth day, the training proper begins at the 
Rehabilitation Department. This Department is in the hands of a Specialist, with specially trained Sister and Nurses. Patients with all kinds of disability are treated in the Department.

The Sister and Nurses responsible for the training of the uniocular patients have been taught the physiology of uni-ocular perception of depth.

*A. Extrinsic Factors (1) Psychological (a) Aerial perspective. (b) Distribution of light and shade. (c) Overlapping of contours. (d) Geometric perspective. (e) Interpretation of size. (These can all be demonstrated by the choice of a good coloured landscape painting). (2) Parallactic Displacement.

B, Adjustment Factoŕs. (1) Effort of accommodation. (2) Measurement by "estimation."

They also know the patients' difficulties. (1) Psychological. (a) "Loss of sight in one eye means loss of half his vision." (b) "Strain on the remaining eye." (2) Physiological. (a) Loss of a small amount of field. (b) Loss of stereoscopic vision.

The notes for the guidance of the trainers are as follows. Some people have a "master eye," i.e., one which they use more than the other, although both may have good vision. Such patients will have greater difficulty in adjusting to the uni-ocular state, if the master eye is put out of action.

Treatment. (1) Psychological. (a) Encouragement, because the loss of sight is not really great. He must not be allowed to think that he is blind. Therefore, mixing with patients with other disabilities is good for him. (b) Either one of paired organs is quite capable of taking on the functions of both without injury to itself, e.g., right-handedness, or one kidney.

(2) Physiological (a) The loss of field is relatively small, and this difficulty can be overcome by a slight false torticollis, and by keeping known objects on the blind side, such as by walking next to the railings in the street. The patient can take exercise in walking to avoid objects and touch others en route. (b) The loss of perception of depth is very real, and constitutes the main difficulty to overcome. Explanation of the extrinsic factors which make for conception of depth should help the patient, especially for estimating distant objects. But for nearer things, for instance, the depth of a step up or down, "practice makes perfect."

The patient can do gymnastics, climbing up and down wall ladders, and stepping over objects on the floor. This helps to keep him fit in body, and, in company with other disabled persons, to take him out of himself.

To hasten the time when the patient can resume a remunerative occupation, hand-and-eye training is essential. The following exercises become progressively more difficult.

- DUkE-Elder.-Text-Book of Ophthalmology, Vol. F. 
" Knitting Nancy" (cotton reel knitting).

Peggity, or a similar game.

Sewing canvas.

Rawlplugs and screws.

Hammering nails.

Carpentry or other hand work.

Ping-pong.

Treatment is given daily, and the patients are purposely not taught things ordinarily done by the blind.

It has been found that the above treatment provides a stimulating and interesting mixture of work and play. It necessitates a slightly longer stay in Hospital, say ten days to a fortnight in all. But the patients go out in a much better frame of mind.

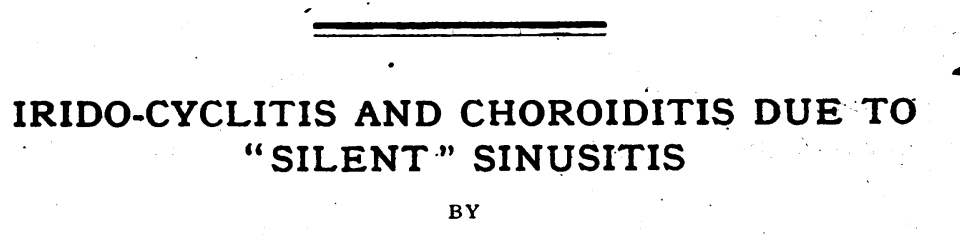

ROSA FORD

LONDON

THE aetiology of irido-cyclitis and choroiditis is admittedly baffling and our views correspondingly speculative.

The following five cases are reported because they show :-

A. (Cases 1 and 2) that the cause may be extremely elusive, even with every advantage for expert diagnosis during many years.

B. (Cases 3 to 5 ) that recognition of a focus of infection in the sinuses, even when there is no other evidence of its existence, may lead to prompt and permanent cure.

CASE 1.-A woman aged 42 years, had her first attack of iritis in the left eye at 12. By 18 she had lost the sight of that eye. The right eye became affected at 24. When first seen in 1935, there were extensive areas of choroidal atrophy in both fundi, with posterior synechiae in the right eye, vision in which was $2 / 18$. Attacks of pain had continued to recur and she had been in regular attendance at one of the London Teaching Hospitals during the 30 years, passing successively under the care of three ophthalmic surgeons and four physicians. None of the many kinds of investigations and treatment tried had been of any avail either in determining the cause or checking the recurrences. CASE $2^{1}$. - A man aged 49 years, first seen in 1920. He remained under observation for 16 years, during which a central choroiditis spread from a few small lesions to extensive areas of choroidal 